\title{
Carers' knowledge of treatment of severe acute malnutrition at Dadaab refugee complex, Kenya: A prospective cohort study
}

\author{
A M Mbogo, ${ }^{1}$ BSc (Food, Nutrition \& Dietetics), MSc (Nutrition); E van Niekerk, ${ }^{2}$ BSc Diet, MSc (Dietetics), PhD; \\ I Ogada, ${ }^{3} \mathrm{PhD} ; \mathrm{C}$ Schübl, ${ }^{4} \mathrm{BSc}$ (Nutrition) \\ ${ }^{1}$ Nutrition Department, Kenyatta National Hospital, Nairobi, Kenya \\ ${ }^{2}$ Department of Global Health, Division of Human Nutrition, Faculty of Medicine and Health Sciences, Stellenbosch University, Cape Town, \\ South Africa \\ ${ }^{3}$ Department of Applied Human Nutrition, Mount Saint Vincent University, Halifax, Canada \\ ${ }^{4}$ Human Nutrition Department, Faculty of Health, Tygerberg Hospital and Stellenbosch University, Cape Town, South Africa
}

Corresponding author: A M Mbogo (mbogoalexander@gmail.com)

\begin{abstract}
Background. Severe acute malnutrition causes half of the deaths in children under the age of 5 years in refugee camps.
Objective. To describe carers' knowledge of the treatment of severe acute malnutrition at Dadaab Refugee Complex in Garissa County, Kenya.

Methods. A prospective cohort study of 128 children (6 - 59 months) and their carers was conducted at the Ifo I and Hagadera refugee camps, Kenya. Child-carer pairs from the stabilisation centre (SC) $(n=22)$ and outpatient therapeutic feeding programme (OTFP) $(n=42)$ at each camp were followed up until discharged. Data were collected using a structured questionnaire. Statistical analyses included $\chi^{2}$ and independent-sample $t$-tests.

Results. The mean (standard deviation) length of stay in the SC was 10.4 (6) days at Ifo and 9.5 (4) days at Hagadera ( $p=0.465)$, while 5.9 (1.5) days and 5.6 (2.1) days in the OTFPs at Ifo and Hagadera, respectively ( $p=0.125)$. There were no defaulters. More than a third of the carers in each OTFP did not know the duration of treatment $(p=0.000)$ and less than half adhered strictly to the prescribed therapeutic feeding recommendations. Only $36 \%$ of carers in the SC at Ifo $(n=8)$ and $27 \%(n=6)$ at Hagadera knew why malnourished children have to be kept warm during cold weather $(p=0.003)$, compared with $48 \%(n=20)$ and $36 \%(n=15)$ of carers in the OTFPs $(p=0.000)$.

Conclusion. Carers have a critical role in managing acute malnutrition in a community-based model. This study provides invaluable insights regarding carers' knowledge on treatment of acute malnutrition and identifies areas of improvement.
\end{abstract}

S Afr J Child Health 2020;14(3):110-114. https://doi.org/10.7196/SAJCH.2020.v14.i3.1567

Globally, about 55 million children under the age of 5 years (10\%) are undernourished. Of these, 19 million suffer from severe acute malnutrition (SAM).$^{[1]}$ SAM contributes to about one million deaths every year in children under the age of 5 years. ${ }^{[1,2]}$ Most SAM cases are from sub-Saharan Africa and South Asia. ${ }^{[3]}$ The prevalence of SAM is generally higher in emergency contexts and contributes to about half of the deaths in children under the age of 5 years in refugee camps. ${ }^{[4]}$

Initially, therapeutic feeding centres treated SAM cases through inpatient care. They admitted all children with SAM, with or without medical complications. This approach was associated with high mortality and default rates. ${ }^{[4]}$ To address setbacks associated with this approach, the community-based management of acute malnutrition (CMAM) model was globally adopted in 2007 and implemented the same year in Kenya. ${ }^{[5,6]}$

CMAM entails treatment of SAM cases at community level using ready-to-use therapeutic foods. In this model, SAM cases without medical complications are treated as outpatients in an outpatient therapeutic feeding programme (OTFP) and those with medical complications are treated as inpatients at stabilisation centres (SCs). ${ }^{[7]}$ Programmes that integrate the CMAM model in an existing health system are referred to as integrated management of acute malnutrition. ${ }^{[5]}$ In Kenya, such integrated programmes are implemented in both rural areas and refugee camp settings using the same national treatment guidelines. However, despite successes being reported through the implementation of the CMAM model, poor treatment outcomes, such as high default rates and long recovery periods, are still being reported. ${ }^{[2,4,8]}$

Studies from paediatric clinical settings suggest that carers' lack of understanding on the nature of treatment may contribute to poor adherence to treatment modalities. ${ }^{[9,10]}$ No studies have assessed carers' understanding of the nature of treating acute malnutrition in a refugee population. The aim of this study was therefore to describe carers' knowledge of treating SAM at the Dadaab refugee complex.

\section{Methods}

Study setting

The study was conducted between 21 May and 31 July 2015 at the Dadaab refugee complex in Garissa County, Kenya. The complex consists of four refugee camps, namely Hagadera, Dagahaley, Ifo I and Ifo II. The majority (97.5\%) of the refugees are of Somalian nationality. ${ }^{[1]]}$ Two camps (Ifo I and Hagadera) were randomly selected from the four sites. At the time of the study, Hagadera had a population of $\sim 106751$ adults and 21351 children under the age of 5 years, while the Ifo camp had a population of 84269 adults and 16854 children under the age of 5 years. ${ }^{[12,13]}$

CMAM services were provided by the International Rescue Committee and Islamic Relief Kenya. Each camp had a CMAM 
programme consisting of one SC, which treated children with SAM and associated medical complications, four OTFPs for children with SAM but without medical complications, and four supplementary feeding programmes, which treated children with moderate acute malnutrition. The study was conducted at the SC and two randomly selected OTFP sites (from the four available) at both Ifo and Hagadera.

\section{Study population}

A sampling list of eligible study participants was developed per study site based on the medical registers from the SC and OTFP. Simple random sampling was used to identify child-carer pairs. Children from an SC were eligible for inclusion in the study if they were admitted with a mid-upper arm circumference $<11.5 \mathrm{~cm}$ or a weight-for-height $z$-score $<-3$, had medical complications and were in Phase II at the time of the study. (Children in Phase II had spent at least 5 days at the SC receiving treatment.) Carers who consented to participate in the study were included with their children to form child-carer pairs.

Children from an OTFP were eligible for inclusion in the study if they were admitted with a mid-upper arm circumference $<11.5 \mathrm{~cm}$ or a weight-for-height $z$-score $<-3$, did not have medical complications and were in the second week of treatment.

The total sample size was 128 child-carer pairs, made up of 64 pairs from each of the two refugee camps. In each group of 64 pairs, 22 childcarer pairs were selected from the SC and 21 pairs from each of the two selected OTFPs at the camp. In the SC programme, enrolled childcarer pairs were followed up until they met discharge criteria. These criteria included attaining a mid-upper-arm circumference $>11.5 \mathrm{~cm}$ or a weight-for-height $z$-score of at least $<-2$ and a good appetite. In addition, they should not have exhibited signs of pitting oedema for 10 days since admission or any other medical complications. Patients admitted to the OTFP were considered to have met discharge criteria if they had maintained a weight-for-height $z$-score of at least $<-2$ or a mid-upper-arm circumference $>11.5 \mathrm{~cm}$, did not show signs of oedema on two consecutive weekly visits and had been in the programme for at least 8 weeks. ${ }^{[6]}$

\section{Study procedure and data collection}

Each SC and OTFP site was managed by a nutritionist, a medical doctor, a nutrition nurse and two nutrition assistants. Nutrition education sessions were delivered by the nutrition nurse and nutrition assistants, and covered the key messages outlined in the Kenyan National Guidelines for Acute Malnutrition. According to this guideline, both SC and OTFP caregivers are supposed to feed their children only on a prescribed amount of therapeutic feeds. They are also required to always cover their children to keep them warm. ${ }^{[6]}$ SC sites operated 24 hours a day and carers were involved in their children's treatment by feeding their children at prescribed feeding frequencies and with appropriate quantities according to the management regimens. Carers in the OTFPs were expected to bring their children for weekly reviews and continue providing therapeutic feeds at home as indicated in the prescribed regimens.

A structured, researcher-administered questionnaire was used to collect data from patients during Phase II of the SC programme and during the third week after admission at OTFP sites. Data collected included sociodemographic information, length of stay, default rates and carers' knowledge on:

- the anticipated duration of the child's treatment

- appropriate administration of therapeutic feeds

- prevention of hypothermia.
Research assistants subsequently conducted daily follow-up visits at the SC and weekly follow-up visits at the OTFP sites to record how carers provided the prescribed therapeutic feeds to their children.

Research assistants received one day's training on interviewing techniques, data collection tools and procedures before implementation of the study. The research instruments were pretested before data collection. Data collection was closely supervised and monitored to ensure reliability and validity. Data were analysed using the SPSS version 21 (IBM Corp., USA). $\chi^{2}$ and independent-samples $t$-tests were used for statistical comparisons between the groups. A significance level of $p<0.05$ was used.

\section{Ethical considerations}

Ethical approval was granted by the Health Research Ethics Committee at Stellenbosch University, South Africa (ref. no. S14/06/133) and the Research Ethics Committee at Kenyatta University, Kenya (ref. no. PKU/307/E283), and further licensed by the National Commission of Science, Technology and Innovation, Kenya (ref. no. NACOSTI/P/15/4871/5678). Voluntary informed consent was obtained from caregivers whose children met the eligibility criteria and agreed to participate in the study. For confidentiality, each participant was assigned a unique identification code during data collection and analysis, rather than their actual names being used.

\section{Results}

A total of 128 children were recruited, with 64 children from each of the two refugee camps. From each group of 64, 22 children were from the SC programme and 21 children were selected from each of the two OTFP sites. There was no loss to follow-up.

\section{Sociodemographic and clinical characteristics}

Table 1 shows the characteristics of the participants from the SC programme. There were no defaulters. The mean (standard deviation (SD)) length of stay was 10.4 (6) days and 9.5 (4) days at

Table 1. Sociodemographic characteristics of participants from the stabilisation centre programme

\begin{tabular}{|c|c|c|c|}
\hline Characteristics & $\begin{array}{l}\text { Ifo }(N=22) \\
n(\%)^{\star}\end{array}$ & $\begin{array}{l}\text { Hagadera } \\
(N=22), \\
n(\%)^{*}\end{array}$ & $p$-value \\
\hline $\begin{array}{l}\text { Children's age } \\
\text { (months), median } \\
\text { (IQR) }\end{array}$ & $10.5(10-15)$ & $15.5(9.8-24)$ & 0.537 \\
\hline \multicolumn{4}{|l|}{ Children's sex } \\
\hline Male & $7(32)$ & $9(41)$ & 0.531 \\
\hline Female & $15(68)$ & $13(59)$ & \\
\hline $\begin{array}{l}\text { Length of stay (days), } \\
\text { mean (SD) }\end{array}$ & $10.4(6)$ & $9.5(4)$ & 0.465 \\
\hline Default rate & 0 & 0 & - \\
\hline $\begin{array}{l}\text { Carers' age (years), } \\
\text { mean (SD) }\end{array}$ & $26.1(5)$ & $29.6(5)$ & 0.019 \\
\hline \multicolumn{4}{|l|}{ Carers'sex } \\
\hline Male & $1(5)$ & 0 & 0.321 \\
\hline Female & $21(95)$ & $22(100)$ & \\
\hline \multicolumn{4}{|l|}{ Carers' level of education } \\
\hline Informal & $19(86)$ & $19(95)$ & 0.488 \\
\hline Primary & $2(9)$ & $1(5)$ & \\
\hline Secondary & $1(5)$ & - & \\
\hline
\end{tabular}


the Ifo and Hagadera camps, respectively $(p=0.465)$. Less than $20 \%$ of carers at either camp had formal education.

Table 2 shows the characteristics of the participants from the OTFP sites. The mean (SD) length of stay was 5.9 (1.5) weeks and 5.6 (2.1) weeks at the Ifo and Hagadera camps, respectively $(p=0.125)$. Less than a third of carers at either camp had formal basic education.

\section{Carers' knowledge of the factors affecting treatment outcomes in severe acute malnutrition Duration of treatment}

As shown in Table 3, more than $70 \%$ of carers participating in the SC programme at the respective sites did not know how long their children would be receiving treatment. More than a third of carers whose children were treated at OTFP sites were unable to say how long their children's treatment would last (Ifo: $n=14 ; 33 \%$; Hagadera: $n=18 ; 43 \%)(p=0.000)$.

\section{Carers' knowledge of appropriate administration of therapeutic feeds}

As shown in Table 4, fewer carers from the Hagadera OTFP $(n=7$; $16 \%)$ knew the correct frequency of prescribed therapeutic feeds than those from the OTFP at Ifo $(n=31 ; 72 \%)(p=0.000)$. In both OTFPs, less than half of the carers fed their children strictly on the prescribed therapeutic feeds. There was a significant relationship between carers' level of education and their knowledge of the frequency of therapeutic feeds in both the SC programme and the OTFP at the two refugee camps ( $p=0.002$ and $p=0.003$, respectively).

\section{Carers' responses on prevention of hypothermia}

Knowledge about the reason for keeping a malnourished child warm during cold weather was significantly different between carers from the two camps, in both programmes (SC: $p=0.003$; OTFP: $p=0.000$ ) (Table 5).

\section{Discussion}

At both camps the majority of carers were female, without formal basic education. In Somali communities, schooling is preferentially

Table 2. Sociodemographic characteristics of participants from the outpatient therapeutic feeding programme $(N=84)$

\begin{tabular}{llll}
\hline Characteristics & $\begin{array}{l}\text { Ifo }(N=42), \\
n(\%)\end{array}$ & $\begin{array}{l}\text { Hagadera } \\
(N=42), n(\%)\end{array}$ & $p$-value \\
\hline $\begin{array}{l}\text { Children's age } \\
\text { (months), median }\end{array}$ & $10.5(9-14)$ & $9(7-18)$ & 0.038 \\
$\begin{array}{l}\text { (IQR) } \\
\text { Children's sex }\end{array}$ & & & \\
$\quad$ Male & $16(38)$ & $18(43)$ & 0.657 \\
$\quad$ Female & $26(62)$ & $24(57)$ & \\
$\begin{array}{l}\text { Length of stay } \\
\text { (weeks), mean (SD) }\end{array}$ & $5.9(1.5)$ & $5.6(2.1)$ & 0.125 \\
$\begin{array}{l}\text { Default rate } \\
\text { Carers' age (years), } \\
\text { mean (SD) }\end{array}$ & 0 & 0 & - \\
Carers' sex & $27.9(7)$ & $26.9(8)$ & 0.561 \\
$\quad \begin{array}{l}\text { Male } \\
\text { Female }\end{array}$ & 0 & & \\
Carers' education level & $100(100)$ & $40(95)$ & 0.152 \\
$\quad \begin{array}{l}\text { Informal education } \\
\text { Primary education }\end{array}$ & $28(67)$ & $34(81)$ & 0.136 \\
CI = confidence interval; SD $=$ standard deviation. &
\end{tabular}

accessible to male children, leading to a small proportion of women with formal education. ${ }^{[14]}$ The finding in our study is consistent with that from a non-refugee population study in northern Ethiopia, which found that the majority of carers of children with SAM had a low literacy level. ${ }^{[15]}$

In both SC programmes, the mean (SD) length of stay was longer than the recommended duration of $7-10$ days, ${ }^{[7]}$ namely 10.4 (6) days at Ifo and 9.5 (4) days at Hagadera. Although no comparable studies were found for refugee populations, the finding reported here is consistent with that of a study among paediatric SAM inpatients conducted in northern India, which reported a mean (SD) length of stay of 11.7 (7.6) days. ${ }^{[16]}$ However, a median of 10 days was reported in a similar study from Lusaka, Zambia. ${ }^{[17]}$ The longer stays in the SC programmes may be attributed to admission of critically ill SAM cases, which took longer to respond to treatment.

At both camps, the length of stay at OTFP sites was about 2.5 weeks shorter than the recommended minimum of 8 weeks. ${ }^{[7]}$ Studies conducted in OTFPs in north and southwest Ethiopia and Yemen reported a mean length of stay of 45 days, 50 days and 40 days, respectively. ${ }^{[15,18,19]}$ Although early discharge may be associated with relapses of SAM cases, longer stays in a CMAM programme, especially in the case of an OTFP, may be associated with defaulting. ${ }^{[7,20]}$ The shorter stays observed in the OTFPs in this study may be attributed to early discharges following good responses to treatment.

There were no defaulters in either the SC programme or the OTFP. According to the SPHERE standards, a default rate of less than $15 \%$ is acceptable in both an SC programme and an OTFP. $^{[4]}$ A recent analysis report on the humanitarian crisis in South Sudan indicated a default rate of $5 \%$ in SC programmes across the country. Low default rates were also reported in a survey conducted among a non-refugee population in inpatient centres for acutely malnourished children with medical complications in South Sudan. ${ }^{[21,22]}$ Similarly a review of routine data from OTFPs at the Mile and Kounoungou refugee camps reported low default rates $\left(4.8 \%\right.$ and $7.0 \%$, respectively). ${ }^{[23]}$ In the current study, the lack of defaulters in either the SC programme or the OTFPs may be attributed to shorter stays.

The majority of carers did not know the estimated duration of their child's treatment, either at the SC programmes or the OTFPs. Studies among non-refugee populations have reported defaulting to be associated with carers' poor understanding of treatment duration, ${ }^{[8]}$ although this was not seen in the current study. Carers' understanding of the estimated duration of treatment is important, particularly in an OTFP, as participants are expected to attend regular monitoring sessions for at least 8 weeks during which the feeds can be replenished. Failure to attend these sessions would compromise treatment. As carers are faced with several opportunity costs, it is important that the estimated duration of treatment and the carer's role in treatment should be explained well.

Significantly more carers from the Ifo camp, in both the SC programme and the OTFP, knew the required quantities and frequency of prescribed feeds than carers from the Hagadera camp. This may be attributed to better orientation and follow-up of carers at the Ifo camp with regard to appropriate administration of therapeutic feeds. The significant relationship observed between carers' level of education and their knowledge of the frequency of therapeutic feeds, across both programme types, suggests a possible effect of literacy level in treatment compliance. Healthcare workers therefore may need to understand literacy and numerical skills of carers to help them implement the treatment appropriately, especially in the case of OTFPs. 
Table 3. Carers' knowledge of the duration of treatment in the respective programmes

\begin{tabular}{lllllll}
\hline & \multicolumn{3}{c}{ Stabilisation centre } & & \multicolumn{2}{c}{$\begin{array}{c}\text { Outpatient therapeutic } \\
\text { feeding programme }\end{array}$} \\
\cline { 2 - 3 } & $\begin{array}{l}\text { Ifo } \\
(N=22),\end{array}$ & $\begin{array}{l}\text { Hagadera } \\
(N=22),\end{array}$ & & $\begin{array}{l}\text { Ifo } \\
(N=42),\end{array}$ & $\begin{array}{l}\text { Hagadera } \\
(N=42),\end{array}$ & \\
Response option & $n(\%)$ & $n(\%)$ & $p$-value & $n(\%)$ & $n(\%)$ & $p$-value \\
\hline$<1$ week & $1(5)$ & $1(5)$ & 0.550 & $3(7)$ & $2(5)$ & 0.000 \\
1 week & 0 & $2(9)$ & & $3(7)$ & $7(17)$ & \\
2 weeks & $2(9)$ & $2(9)$ & & $1(2.4)$ & $9(21)$ & \\
$<1$ month & 0 & 0 & $2(4.8)$ & $4(10)$ & \\
$>1$ month & 0 & 0 & $19(45)$ & $2(5)$ & \\
Did not know & $19(86)$ & $17(77)$ & & $14(33)$ & $18(42)$ &
\end{tabular}

Table 4. Carers' knowledge regarding administration of the therapeutic feeds

\begin{tabular}{llllllll}
\hline & \multicolumn{3}{c}{ Stabilisation centre } & & \multicolumn{3}{c}{$\begin{array}{l}\text { Outpatient therapeutic } \\
\text { feeding programme }\end{array}$} \\
\cline { 2 - 4 } & $\begin{array}{l}\text { Ifo } \\
(N=22),\end{array}$ & $\begin{array}{l}\text { Hagadera } \\
(N=22),\end{array}$ & & $\begin{array}{l}\text { Ifo } \\
(N=42),\end{array}$ & $\begin{array}{l}\text { Hagadera } \\
(N=42),\end{array}$ \\
Response option & $n(\%)$ & $n(\%)$ & $p$-value & $n(\%)$ & $n(\%)$ & $p$-value \\
\hline $\begin{array}{l}\text { Knew accurate } \\
\text { quantities of feeds }\end{array}$ & $22(100)$ & $22(100)$ & - & $37(88)$ & $23(55)$ & 0.000 \\
$\begin{array}{l}\text { Knew correct } \\
\text { frequency of feeds }\end{array}$ & $22(100)$ & $13(59)$ & 0.001 & $31(74)$ & $7(17)$ & 0.000 \\
$\begin{array}{l}\text { Strictly gave } \\
\text { only prescribed } \\
\text { therapeutic feeds }\end{array}$ & $20(91)$ & $14(64)$ & 0.031 & $8(19)$ & $19(45)$ & 0.012 \\
\end{tabular}

Table 5. Carers' knowledge of the reason for keeping a malnourished child warm during cold weather

\begin{tabular}{|c|c|c|c|c|c|c|}
\hline \multirow[b]{2}{*}{ Response option } & \multicolumn{3}{|c|}{ Stabilisation centre } & \multicolumn{3}{|c|}{$\begin{array}{l}\text { Outpatient therapeutic } \\
\text { feeding programme }\end{array}$} \\
\hline & $\begin{array}{l}\text { Ifo } \\
(N=22), \\
n(\%)\end{array}$ & $\begin{array}{l}\text { Hagadera } \\
(N=22), \\
n(\%)\end{array}$ & $p$-value & $\begin{array}{l}\text { Ifo } \\
(N=42), \\
n(\%)\end{array}$ & $\begin{array}{l}\text { Hagadera } \\
(N=42), \\
n(\%)\end{array}$ & $p$-value \\
\hline Thin and weak & $13(59)$ & $5(23)$ & 0.003 & $6(14)$ & $3(7)$ & 0.000 \\
\hline $\begin{array}{l}\text { Die easily if } \\
\text { exposed to cold }\end{array}$ & $8(36)$ & $6(27)$ & & $20(48)$ & $15(36)$ & \\
\hline $\begin{array}{l}\text { Unable to cover } \\
\text { themselves }\end{array}$ & 0 & $10(45)$ & & $6(14)$ & $24(57)$ & \\
\hline $\begin{array}{l}\text { Other: To prevent } \\
\text { pneumonia }\end{array}$ & $1(5)$ & 0 & & $10(24)$ & 0 & \\
\hline $\begin{array}{l}\text { Did not know the } \\
\text { reason }\end{array}$ & 0 & $1(5)$ & & 0 & 0 & \\
\hline
\end{tabular}

Better compliance with regard to the use of the prescribed therapeutic feeds as the only food for malnourished children was seen in the SC programme than in the OTFPs, and specifically so at Ifo. This observation may be attributed to better sensitisation of healthcare workers and close monitoring of feeding. Poor compliance in OTFPs may be due, in part, to children being treated at home, where family food is readily available. A lack of direct monitoring by healthcare workers likely compromises carers' adherence to feeding instructions. Better compliance observed in the SC at Ifo may be attributed to better sensitisation of healthcare workers and close monitoring of feeding.

We did not find other studies that explored therapeutic feeding or knowledge on therapeutic feeds in refugee populations. Studies in clinical settings among children with other conditions indicate that treatment non-adherence among carers is partly associated with a lack of knowledge on the nature of treatment. ${ }^{[10,23]}$ Use of other foods during the treatment period will likely compromise the caloric and nutrient intake required for catch-up growth in acutely malnourished children. This may contribute to poor weight gain and consequently a longer stay in a programme. Apart from therapeutic feeds serving as treatment in the management of acute malnutrition, they are also the only food that acutely malnourished children should consume for optimal recovery. ${ }^{[6]}$ For this reason, regular education and counselling on the use of therapeutic feeds should be offered to carers at both refugee camps.

The majority of carers, in both programmes (SC and OTFP) and across both camps, did not understand the reason for having to keep acutely malnourished children warm during cold weather. This may be attributed to carers receiving inadequate health education or a lack of follow-up messages about the prevention and management of hypothermia in acutely malnourished children. Hypothermia is associated with a high mortality rate among acutely malnourished children. ${ }^{[9,24]}$ Regular sensitisation about preventing hypothermia is advised for carers across both programmes and at both camps.

\section{Limitations of the study}

The findings from this study may not generally apply to other refugee populations.

\section{Conclusion}

Carers have a critical role in the management of SAM in a community-based management model. The current study provides valuable insight into carers' knowledge of the treatment process and identifies areas for improved education.

Declaration. This manuscript was submitted in partial fulfilment of the requirements for a MSc (Nutr) degree.

Acknowledgements. We thank Stellenbosch University (South Africa) for facilitating the study and the National Commission for Science, Technology and Innovation (Kenya) for permission to conduct the research in Kenya. We are also grateful to the Department of Refugee Affairs, the Kenya Red Cross, Islamic Relief in Kenya, the International Rescue Committee, the United Nation High Commission for Refugees and the government of Garissa County for their support during data collection. We acknowledge the work of the research assistants during data collection and also thank the study participants for their voluntary participation. 
Author contributions. AM developed the study protocol, collected the data, participated in data analysis (assisted by a statistician from Stellenbosch University) and compiled the final report. EvN, IO and CS supervised the development of the protocol and provided input during manuscript development.

Funding. Funding for this study was provided by the Stellenbosch University Rural Medical Education Partnership Initiative (SURMEPI) and the President's Emergency Plan for AIDS Relief (PEPFAR).

Conflicts of interest. None.

1. World Health Organization, World Food Programme, United Nations System Standing Committee on Nutrition, United Nations Children's Fund. Communitybased management of severe acute malnutrition. Geneva: WHO, 2007. http:// www.who.int/nutrition/topics/Statement_community_based_man_sev_acute_ mal_eng.pdf (accessed 19 July 2016).

2. Prudhon C, Briend A, Prinzo ZW, Daelmans B, Mason JB. Proceedings of the WHO, UNICEF and SCN informal consultation on community-based management of severe malnutrition in children. Food Nutr Bull 2006:27(3 Supplement):S1-S108. https://www.who.int/nutrition/publications/severe malnutrition/FNB_0379-5721.pdf?ua=1 (accessed on 19 April 2016)

3. Shoham J, Dolan C, Gostelow L. Managing acute malnutrition at scale : A review of donor and government financing arrangements. London: Overseas Development Institute, 2013. https://odihpn.org/resources/managing-acute-malnutrition-atscale-a-review-of-donor-and-government-financing-arrangements (accessed 19 April 2018).

4. Doocy S, Tappis H, Haskew C, Wilkinson C, Spiegel P. Performance of UNHCR nutrition programs in post-emergency refugee camps. Conflict Health 2011;5:23. https://doi.org/10.1186/1752-1505-5-23

5. United Nations Children's Fund. Evaluation of community management of acute malnutrition (CMAM): Ethiopia Country Case Study. New York: Unicef, 2012. https://www.unicef.org/evaldatabase/files/CMAM_Final_Ethioia.pdf (accessed 19 April 2016).

6. Government of Kenya. National guideline for integrated management of acute malnutrition. Nairobi: Ministry of Health, 2009. http://www.severemalnutrition. org/sites/default/files/Kenya-MoH-IMAM-Guideline-June-2009.pdf (accessed 10 May 2016).

7. Emergency Nutrition Network. Module 13 Management of severe acute malnutrition. https://www.ennonline.net/attachments/2048/HTP-v2-module13-technical-notes.pdf (accessed 13 November 2016).

8. Van der Velden E. Improving default-rates: Improving default rates in ambulatory therapeutic feeding programmes in operations by Médecins sans Frontières Operational Centre Amsterdam. MIH thesis. Amsterdam: KIT Royal Tropical Institute/Vrije Universiteit Amsterdam, 2008:1-87. http://www.bibalex.org/ search4dev/files/350721/183306.pdf (accessed 12 March 2016).

9. Deb S, Dhar S, Parikh D. The role of patient (parent) education and counseling in pediatric dermatology practice. Indian J Paediatr Dermatol 2015;16(3):117-121. https://doi.org/10.4103/2319-7250.160662

10. El-Rachidi S, LaRochelle JM, Morgan JA. Pharmacists and pediatric medication adherence: Bridging the gap. Hosp Pharm 2017;52(2):124-131. https://doi. org/10.1310/hpj5202-124
11. United Nations High Commissioner for Refugees. Nutrition surveys: Dadaab Refugee Camps. Hagadera, Ifo, and Dagahaley camps and Dagahaley outskirts. Geneva: UNHCR, 2011. http://sens.unhcr.org/wp-content/uploads/2015/03/ Tool_05_SENS_Pre-Module_DADAAB_SURVEY_REPORT_2011_v2.pdf (accessed 19 April 2018)

12. ReliefWeb. Ifo Camp profile, Dadaab Refugee Camps, Kenya. https://reliefweb. int/report/kenya/ifo-camp-profile-dadaab-refugee-camps-kenya (accessed 10 May 2016).

13. ReliefWeb. Hagadera Camp Profile, Dadaab Refugee Camps, Kenya. https:// reliefweb.int/sites/reliefweb.int/files/resources/HagaderaCampProfile_ DadaabKenyaAugust2015.pdf (accessed 10 May 2016 ).

14. INTERSOS, Somalia. Barriers to girls' education in South-Central Somalia. https://www.intersos.org/wp-content/uploads/2017/09/barriers-to-girlseducation-in_south-central-somalia-annex-1.pdf (accessed 10 January 2019).

15. Desalegn M, Kifle W, Birtukan T, Amanuel T. Treatment outcome of severe acute malnutrition and determinants of survival in Northern Ethiopia: A prospective cohort study. Int J Nutr Metab 2016;8(3):12-23. https://doi. org/10.5897/ijnam2015.0193

16. Irena AH, Mwambazi M, Mulenga V. Diarrhea is a major killer of children with severe acute malnutrition admitted to inpatient set-up in Lusaka, Zambia. Nutr J 2011;10(1):110. https://doi.org/10.1186/1475-2891-10-110

17. Singh P, Kumar P, Rohatgi S, Basu S, Aneja S. Experience and outcome of children with severe acute malnutrition using locally prepared therapeutic diet. Indian J Pediatr 2016;83(1):3-8. https://doi.org/10.1007/s12098-015-1818-z/

18. Muftah S. Outpatient management of severe acute malnutrition among children under five years old in Yemen: A retrospective cohort study. Int J Contemp Pediatrics 2016;3(2):445-451. https://doi.org/10.18203/2349-3291. ijcp20161026 (accessed 9 April 2016).

19. Shanka NA, Lemma S, Abyu DM. Recovery rate and determinants in treatmen of children with severe acute malnutrition using outpatient therapeutic feeding program in Kamba District. J Nutr Disord Ther 2015;5(2):155. https://doi. org/10.4172/2161-0509.1000155

20. Mbaya D, Bitok LK, Karani AK, Osano B, Habtu M. Outcomes of severely malnourished children aged 6 - 59 months on outpatient management program in Kitui County Hospital, Kenya. Open J Peadiatr 2015;5(4):326-333.

21. Saaka M, Osman SM, Abdul-Mumin A, et al. Clinical outcomes and determinants of recovery rates of pediatric inpatients treated for severe acute malnutrition. Int J Child Health Nutr 2015;4(4):219-229. https://doi. org/10.6000/1929-4247.2015.04.04.4

22. Ndzo JA, Jackson A. Outcomes of children aged 6-59 months with severe acute malnutrition at the GADO Outpatient Therapeutic Center in Cameroon. BMC Res Notes 2018;11(1):68. https://doi.org/10.1186/s13104-018-3177-0

23. Temere SK. Tackling high defaulting rates in refugee camp settings - lessons from Chad. https://www.ennonline.net/nex/4/en/tackling (accessed 7 January 2019).

24. Talbert A, Atkinson S, Karisa J, Ignas J, Chesaro C, Maitland K. Hypothermia in children with severe malnutrition: Low prevalence on the tropical coast of kenya. J Trop Pediatr 2009;55(6):413-416. https://doi.org/10.4172/21610509.1000155

Accepted 21 October 2019 